\title{
An Econometric Model to Predict Participation in Urban and Community Forestry Programs in South Carolina, U.S.
}

\author{
J. Jess Fleming, Thomas J. Straka, and Stephen E. Miller
}

\begin{abstract}
A regression-based econometric model was generated from a statewide survey of South Carolina, U.S., residents concerning participation in urban and community forestry programs. The econometric model attempts to estimate the probability of an individual's participation. Results are intended to increase effectiveness of program planning and organization within state forestry commissions. Model 1 was created as follows: participation $=F$ (gender, age, education, marital status, region, area raised, area reside, household, duties, and income). Because these responses represented qualitative values, a number of dummy variables ( 0 or 1 , for example, for yes or no) were generated to more accurately reflect the values for participation and a logit model was used. Logit regression analysis produces a value between 0 and 1 that can be interpreted as a probability. Model 2, with fewer variables, was later created to reduce possible multicollinearity problems. Model 1 had a pseudo- $\mathrm{R}^{2}$ value of 0.2955 or a $29.55 \%$ probability of having a correct prediction for participation. Model 2 had a pseudo- $\mathrm{R}^{2}$ value of 0.2407 . The models produced reasonable predictions of participation.

Key Words. Econometrics; public involvement; urban and community forestry.
\end{abstract}

What factors influence participation in urban and community forestry (U\&CF) programs? Which participant characteristics are most predictive of participation levels? How likely is a specific forest owner to participate in the program? Econometrics is a tool that helps answer these questions. Econometrics is "the application of statistical and mathematical methods to the analysis of economic data, with a purpose of giving empirical content to economic theories and verifying them or refuting them" (Maddala 2001). We used econometric methods in this study to assist in U\&CF program planning and to aid in better identifying the factors that affect participation in the program.

At the turn of the century, over three-fourths of U.S. residents lived in urban areas (Alig et al. 1999; U.S. Department of Commerce 2000) and the urban forest has had a significant impact on their quality of life (Alig et al. 2003). Congress realized this when it amended the Cooperative Forestry Assistance Act of 1978 to authorize financial, technical, and related assistance to state foresters in support of cooperative efforts in U\&CF (Cubbage et al. 1993).

Between 1960 and 1997, the nation's urban area increased from 10.2 to 26.7 million ha (25-66 million ac) (Vesterby and Krupa 2001). Over the 48 contiguous states, in 1992, less than $3 \%$ of land area was urban and less than $5 \%$ of the land area was considered developed (Heimlich and Anderson 2001). Urban land area in 1997 varied from $10 \%$ in the
Northeast to $1 \%$ in the Mountain Region (Vesterby and Krupa 2001). Urbanization has been tied to population growth, and by 2050 , another 16.2 million ha (40 million ac) is expected to be converted into urban and other development uses (Alig et al. 2003). South Carolina followed this national trend (London and Hill 2000). This increased urbanization increased the importance of U\&CF programs. Knowledge of the characteristics of people who participate and who do not participate in these programs should allow planners to target an audience for participation.

Assistance from U\&CF programs involves U\&CF planning, recreational development, air and water quality improvement programs, stormwater management, urban wildlife management, and economic, urban development, and conservation management plans. Within the United States, typical program recipients are local governments, policymakers and elected officials, builders and developers, civic and community groups, neighborhood associations, nonprofit groups, local businesses, and urban forest councils (Urban Forestry South Expo 2005).

An important aspect of U\&CF programs is public involvement (SC Forestry Commission 2005). Citizen participation has been shown to be essential to U\&CF program success (Cole 1979; Henderson 1984). With tight budgets and other constraints, volunteerism and public participation are key determinants to program success (Bloniarz and Ryan 1996; 
Sommer 1996). The support of nontraditional audiences is considered crucial to enhancing these programs (Iles 1998) and increased volunteers provide different skills, new ideas, and more effective outreach (Westphal and Childs 1994). For programs like Tree City USA expanded participation is seen as necessary to counter lagging fiscal support (Andresen 1989).

To ensure public participation, one must first establish who the individuals are and when promoting these programs who needs to be targeted. The purpose of this study was to provide insight on continued public participation within the U\&CF programs. The econometric model created in this study will show the likelihood of participation in these programs for individuals based on personal characteristics. The data used in the model were described and analyzed by Straka et al. (2005). We used the same data to develop a predictive model that will help identify factors that impact participation and aid in projecting individual forest owner participation.

Wall et al. (2006) described a similar econometric study. They also attempted to identify factors that led to U\&CF program participation. That study used data from 42 of the states to quantify participation; we used data from a survey of South Carolina residents to attempt to do the same thing. Wall's study attempted to identify variables that impacted participation, whereas this study produced a probability of participation.

\section{STUDY METHODS}

In the fall of 2003, a survey was mailed to 324 South Carolina residents to identify characteristics of participants and nonparticipants in U\&CF programs and their attitudes toward the programs (Straka et al. 2005). Past participants were randomly selected from South Carolina Forestry Commission records, whereas nonparticipants were randomly selected from occupational groups that would be expected to exhibit equal interest in U\&CF programs. The information on the 192 surveys returned was used to generate the econometric model. This is a $59 \%$ response rate; participants were $56 \%$ of the respondents.

Econometrics involves the specification of a regression analysis model that forecasts or explains behavior. We developed an econometric or regression model to predict participation in U\&CF programs. Specific questions answered by both participants and nonparticipants were used to create the independent and dependent variables. "Regression analysis is concerned with describing and evaluating the relationship between a given variable (often called the explained or dependent variable, in our case participation) and one or more other variables (often called the explanatory variables or independent variable)" (Maddala 2001). The responses to each question were placed in a Microsoft Excel document then imported into SAS 9.0 (Statistical Analysis System for Windows) to create the regression model (SAS Institute 2002).

Model formulation needed to describe the dependent variable, participation, was the primary task. The standard regression model using ordinary least squares could not be used because the dependent variable was nonnumeric, that is, questions were answered by responses like "yes" or "no" or "male" or female." A linear probability model was first considered for the analysis with a dichotomous dependent variable, that is, the participation variable would take on a value of 1 or 0 , yes or no, respectively (Maddala 2001). Participation would be an indicator variable that shows the incidence of an event or whether the person participated in the program, and we would have some independent variables that determine the likelihood of participation (Maddala 2001). The qualitative nature of the dependent variable proved inappropriate for the linear probability model.

The logit model creates dummy variables for each of the dependent variables, that is, it accounts for the nonnumeric values by transforming the qualitative values into numeric values ( 0 or 1 ). This is achieved by creating dummy variables for each of the independent variables.

Dummy variables were created to define each independent variable (Table 1). For the independent variable "age," three dummy variables were created. The question was "What is your age?" The possible responses were: a) under 30 years old, b) 30 to 49 years old, c) 50 to 65 years old, or d) 66 years old or older. Of these four answers, three were chosen to become dummy variables. One answer was omitted because its effect can be seen in the models intercept. This approach was used throughout the model. The three answers retained for age were a, b, and d. They were defined as age1, age2, and age 4 .

The logit regression analysis was computed using the SAS 9.0 system. This type of regression returns a numeric value between 0 and 1 (which can be interpreted as a probability or percent) that describes how likely a certain individual (based on characteristics such as gender, age, and education level) will be to participate in U\&CF programs. Once the value for participation of an individual is computed, if it is less than 0.50 , we predicted that individual is not likely to participate in U\&CF programs. Likewise, a value greater than or equal to 0.50 indicated that the individual is likely to participate in U\&CF programs. Another way to interpret the participation value is to consider it a probability. If the value is 0.85 , we predicted the individual will likely participate, but you can also say the individual is $85 \%$ likely to participate in U\&CF programs.

\section{RESULTS AND DISCUSSION}

The logistic regression completed in SAS 9.0 yielded the following model (model 1) for participation: 
Table 1. Independent variable definitions.

\begin{tabular}{|c|c|c|c|}
\hline \multicolumn{2}{|c|}{ Variable } & \multicolumn{2}{|r|}{ Variable } \\
\hline Gender & & Environment raised & \\
\hline Gender & Female & AreaRaised1 & Rural nonfarm \\
\hline Age & & AreaRaised2 & Rural farm \\
\hline Age1 & Under 30 yrs old & AreaRaised4 & Urban \\
\hline Age2 & 30 to 49 yrs old & AreaReside1 & Rural nonfarm \\
\hline Age4 & 66 yrs old or older & AreaReside2 & Rural farm \\
\hline \multicolumn{2}{|c|}{ Highest level of education } & AreaReside4 & Urban \\
\hline Education1 & Elementary school & Type of household & \\
\hline Education2 & High school & Household1 & Family household without children \\
\hline Education3 & Associate 2-yr degree & Household3 & Female householder with children under 18 \\
\hline Education4 & Some college & Household4 & Male householder with children under 18 \\
\hline Education6 & Graduate degree & Household5 & Householder living alone \\
\hline Marital status & & Employment duties & \\
\hline MaritalStatus1 & Never married & Duties2 & Director/coordinator \\
\hline MaritalStatus3 & Separated & Duties3 & Consultant \\
\hline MaritalStatus4 & Widowed & Duties4 & Educator \\
\hline MaritalStatus5 & Divorced & Duties5 & Superintendent/manager \\
\hline \multicolumn{2}{|c|}{ Region in SC where currently living } & Duties6 & Planner \\
\hline Region1 & Upstate & Duties7 & Other \\
\hline \multirow[t]{3}{*}{ Region3 } & Lower Coastal Plain & Household Income & \\
\hline & & Income1 & $\$ 0-30,000$ per year \\
\hline & & Income3 & Greater than $\$ 85,000$ per year \\
\hline
\end{tabular}

Participation $=$ Part $=$ intercept $+\beta_{1}$ Gender $+\beta_{2}$ Age $1+\beta_{3}$ Age $2+\beta_{4}$ Age $4+\beta_{5}$ Education 1

$+\beta_{6}$ Education $2+\beta_{7}$ Education3 $+\beta_{8}$ Education4

$+\beta_{9}$ Education6 $+\beta_{10}$ MaritalStatus $1+\beta_{11}$ MaritalStatus3

$+\beta_{12}$ MaritalStatus $4+\beta_{13}$ MaritalStatus5 $+\beta_{14}$ Region1

$+\beta_{15}$ Region3 $+\beta_{16}$ AreaRaised $1+\beta_{17}$ AreaRaised 2

$+\beta_{18}$ AreaRaised $4+\beta_{19}$ AreaReside $1+\beta_{20}$ AreaReside 2

$+\beta_{21}$ AreaReside $4+\beta_{22}$ Household $1+\beta_{23}$ Household 3

$+\beta_{24}$ Household $4+\beta_{25}$ Household $5+\beta_{26}$ Duties 2

$+\beta_{27}$ Duties3 $+\beta_{28}$ Duties $4+\beta_{29}$ Duties5 $+\beta_{30}$ Duties6

$+\beta_{31}$ Duties $7+\beta_{32}$ Income $1+\beta_{33}$ Income $3+$ error.

The corresponding $\beta$ values can be found in Table 2 . The calculation of the probability for participation in U\&CF programs is best illustrated with an example. Consider a female, age 35 , with a graduate degree, married with two children under 18 years old, living in a rural nonfarm area in the upstate, who lived as a child in a suburbs on the Lower Coastal Plain, and is a forestry consultant with an annual household income is $\$ 150,000$.

Variables that match the individual, like Age2 (because she is 35) become " 1 's" and the other variable become " 0 's." If 1 's are plugged into the appropriate areas of the model, the equation becomes participation $=0.721275+0.782774$ $($ Gender $=1)+0.245537($ Age2 $=1)+0.327203$ (Education6 = 1) $+0.686155($ Region1 $=1)+0.110472($ AreaReside $1=1)-0.043248($ Duties3 $=1)-0.174308($ Income3 $=1)$.

Participation equals 2.65586. In a logit model, the result must be transformed to equal a probability. In this case, the transformation is $\left(\exp ^{\wedge}(2.65586)\right) /\left(1+\exp ^{\wedge}(2.65586)\right)=$ 0.93437125 , which indicates that there is a $93.44 \%$ chance she will participate in U\&CF programs. Sice $0.9344>0.5$, we conclude she will be participating in U\&CF programs.

A likelihood ratio test, based on the $\chi^{2}$ distribution, was used to determine if the model was significant. The likelihood ratio value for the entire model was 43.698. The model proved to be useful at the $10 \%$ significance level because the calculated value of 43.698 is less than the $\chi^{2}$ tabulated value of 43.75 with 33 degrees of freedom.

The next step in interpreting the regression results involved the significance of the individual parameter estimates for the independent variables (Table 3). Significance levels were used to determine if the parameter estimates are significantly different from zero. "It is customary to use 0.05 as a low probability and to reject the suggested hypothesis if the probability of obtaining as extreme a $t$-value as the observed $t_{0}$ is less than 0.05" (Maddala 2001). In our case, the suggested hypothesis (Ho: $\beta_{n}=0$ ) is true (fail to reject) if the approximate probability is less than 0.05 . There were only four variables that were significantly different from 0 for the full model.

This can be misleading when interpreting the results; all of the independent variables are dummy variables, which gives them a value of either 0 or 1 . Because these variables only correspond with 10 questions from the survey, there was a high probability that a particular variable would receive more 0 's than 1's with a sample size of 192. Zeroes indicated that a particular variable was not a characteristic of an individual 
Table 2. Corresponding $\beta$ values for the model 1.

\begin{tabular}{|c|c|c|}
\hline Variable & $\beta$ 's & Numeric value \\
\hline Intercept & $\beta_{0}$ & 0.721275 \\
\hline Gender & $\beta_{1}$ & 0.782774 \\
\hline Age1 & $\beta_{2}$ & -1.872991 \\
\hline Age2 & $\beta_{3}$ & 0.245537 \\
\hline Age4 & $\beta_{4}$ & -0.811006 \\
\hline Education1 & $\beta_{5}$ & -8.57872 \\
\hline Education2 & $\beta_{6}$ & -1.775104 \\
\hline Education3 & $\beta_{7}$ & -0.863352 \\
\hline Education4 & $\beta_{8}$ & -1.167792 \\
\hline Education6 & $\beta_{9}$ & 0.327203 \\
\hline MaritalStatus1 & $\beta_{10}$ & 0.909987 \\
\hline MaritalStatus3 & $\beta_{11}$ & -17.808599 \\
\hline MaritalStatus4 & $\beta_{12}$ & -29.098726 \\
\hline MaritalStatus5 & $\beta_{13}$ & 0.156967 \\
\hline Region1 & $\beta_{14}$ & 0.686155 \\
\hline Region3 & $\beta_{15}$ & 0.182202 \\
\hline AreaRaised1 & $\beta_{16}$ & -0.336653 \\
\hline AreaRaised2 & $\beta_{17}$ & -0.273474 \\
\hline AreaRaised4 & $\beta_{18}$ & 0.098243 \\
\hline AreaReside1 & $\beta_{19}$ & 0.110472 \\
\hline AreaReside2 & $\beta_{20}$ & 0.723733 \\
\hline AreaReside4 & $\beta_{21}$ & 0.092644 \\
\hline Household1 & $\beta_{22}$ & 0.030136 \\
\hline Household3 & $\beta_{23}$ & -1.289152 \\
\hline Household4 & $\beta_{24}$ & -0.711543 \\
\hline Household5 & $\beta_{25}$ & -0.654883 \\
\hline Duties2 & $\beta_{26}$ & -0.615841 \\
\hline Duties3 & $\beta_{27}$ & -0.043248 \\
\hline Duties4 & $\beta_{28}$ & -2.090003 \\
\hline Duties5 & $\beta_{29}$ & -0.551511 \\
\hline Duties6 & $\beta_{30}$ & -0.315801 \\
\hline Duties7 & $\beta_{31}$ & -1.155163 \\
\hline Income1 & $\beta_{32}$ & 1.844188 \\
\hline Income3 & $\beta_{33}$ & -0.174308 \\
\hline
\end{tabular}

and 1's indicated that that variable (characteristic) did not apply. This would suggest why so many parameter estimates appeared to be equal to 0 . Specific groups of individual independent variables were also examined using the likelihood ratio method to determine how different they were from 0 , but these tests were deemed inconclusive to the model for the same reasons described for the individual variables.

There are three pitfalls of econometric models. Each is a potential problem for any regression model, but all are more likely to occur when economic or social data are used in the regression model. One potential problem involves unequal variance in the disturbance terms but was unlikely to occur in our model. A second potential problem is autocorrelation associated with time-series data. Because our data were not from a time series, we did not expect this problem.

A third potential problem is multicollinearity caused by highly correlated independent variables. It can cause large
Table 3. Probabilities for individual parameter estimates.

\begin{tabular}{|c|c|c|c|}
\hline & $\begin{array}{l}\text { Approximate } \\
\text { probability } \\
>1 \mathrm{t} 1\end{array}$ & $\begin{array}{l}\text { Significance } \\
\text { level }\end{array}$ & $\begin{array}{l}\text { Hypothesis test } \\
\text { Ho: } \beta n=0 \\
\text { Ha: } \beta n \neq 0\end{array}$ \\
\hline Intercept & 0.3130 & $5 \%$ & Fail to reject \\
\hline Gender & 0.0971 & $5 \%$ & Fail to reject \\
\hline Age1 & 0.0540 & $5 \%$ & Fail to reject \\
\hline Age2 & 0.5987 & $5 \%$ & Fail to reject \\
\hline Age4 & 0.2469 & $5 \%$ & Fail to reject \\
\hline Education1 & $<0.0001$ & $5 \%$ & Reject \\
\hline Education2 & 0.0453 & $5 \%$ & Reject \\
\hline Education3 & 0.2888 & $5 \%$ & Fail to reject \\
\hline Education4 & 0.1131 & $5 \%$ & Fail to reject \\
\hline Education6 & 0.4643 & $5 \%$ & Fail to reject \\
\hline MaritalStatus1 & 0.4612 & $5 \%$ & Fail to reject \\
\hline MaritalStatus3 & 0.9978 & $5 \%$ & Fail to reject \\
\hline MaritalStatus4 & ,.0001 & $5 \%$ & Reject \\
\hline MaritalStatus5 & 0.8897 & $5 \%$ & Fail to reject \\
\hline Region1 & 0.1702 & $5 \%$ & Fail to reject \\
\hline Region3 & 0.6836 & $5 \%$ & Fail to reject \\
\hline AreaRaised1 & 0.5256 & $5 \%$ & Fail to reject \\
\hline AreaRaised2 & 0.6541 & $5 \%$ & Fail to reject \\
\hline AreaRaised4 & 0.8867 & $5 \%$ & Fail to reject \\
\hline AreaReside1 & 0.8412 & $5 \%$ & Fail to reject \\
\hline AreaReside2 & 0.3347 & $5 \%$ & Fail to reject \\
\hline AreaReside4 & 0.8755 & $5 \%$ & Fail to reject \\
\hline Household1 & 0.9486 & $5 \%$ & Fail to reject \\
\hline Household 3 & 0.5675 & $5 \%$ & Fail to reject \\
\hline Household4 & 0.6728 & $5 \%$ & Fail to reject \\
\hline Household5 & 0.5725 & $5 \%$ & Fail to reject \\
\hline Duties2 & 0.3211 & $5 \%$ & Fail to reject \\
\hline Duties3 & 0.9771 & $5 \%$ & Fail to reject \\
\hline Duties4 & 0.0023 & $5 \%$ & Reject \\
\hline Duties5 & 0.4059 & $5 \%$ & Fail to reject \\
\hline Duties6 & 0.6411 & $5 \%$ & Fail to reject \\
\hline Duties7 & 0.0646 & $5 \%$ & Fail to reject \\
\hline Income1 & 0.0580 & $5 \%$ & Fail to reject \\
\hline Income 3 & 0.6825 & $5 \%$ & Fail to reject \\
\hline
\end{tabular}

standard errors and can make individual correlated variables appear to have weak impacts when, as a group, they have a strong impact (Allison 1999). This problem was possible in our model and we evaluated the problem examining the independent variables (Table 4). There were three pairs of independent variables that were highly correlated: Education1 (elementary school) and MaritalStat4 (widowed), MaritalStat1 and Household5 (living alone), and Region3 (lower coastal) and Region1 (upstate). These three combinations were all correlated higher than 50\%. Each individual variable was examined to determine how it might be affecting the model.

Education1 and all marital status variables were likely sources of multicollinearity and these variables were from the original full model to create a second model (model 2) with 
Table 4. Pearson correlation coefficients.

\begin{tabular}{lllr}
\hline Variable & $\&$ & Variable & Correlation \\
\hline Age1 & $\&$ & MaritalStatus1 & 0.45848 \\
Age2 & $\&$ & Household1 & -0.37135 \\
Age2 & $\&$ & Age4 & -0.32868 \\
Age4 & $\&$ & Region1 & 0.30745 \\
Age4 & $\&$ & Duties7 & 0.34561 \\
Age4 & $\&$ & Income1 & 0.33776 \\
Age4 & $\&$ & MaritalStatus4 & 0.31811 \\
Education1 & $\&$ & MaritalStatus4 & 0.57429 \\
Education3 & $\&$ & Income1 & 0.3072 \\
Education6 & $\&$ & Duties4 & 0.32459 \\
MaritalStatus1 & $\&$ & Household5 & 0.53809 \\
MaritalStatus3 & $\&$ & Household3 & 0.40063 \\
MaritalStatus3 & $\&$ & Household4 & 0.40063 \\
MaritalStatus5 & $\&$ & Household5 & 0.47004 \\
Region3 & $\&$ & Region1 & -0.51711 \\
AreaRaised1 & $\&$ & AreaRaised2 & -0.30023 \\
AreaRaised2 & $\&$ & AreaReside2 & 0.47169 \\
AreaRaised4 & $\&$ & AreaReside4 & 0.34715 \\
AreaReside1 & $\&$ & AreaReside4 & -0.30582 \\
Household1 & $\&$ & Household5 & -0.40581 \\
\hline
\end{tabular}

better explanatory power. The third set of variables that were highly correlated was Region 1 and Region3. These variables are in the same category, which would indicate that they should be correlated. Because these variables can never interact, they were retained in the model. Age1 (under 30) and Duties4 (educator) proved to be significant at the 5\% level indicating that these variables have a large effect on participation.

The next step in defining the model dealt with goodness of fit as measured by $R^{2}$. Because the model in this study is logistic, the normal $\mathrm{R}^{2}$ value cannot be used. We used pseudo- $\mathrm{R}^{2}$ measures (Maddala 2001). The Cragg-Uhler $\mathrm{R}^{2}$ is an appropriate pseudo- $\mathrm{R}^{2}$ formula for a logistic model with 0 to 1 values that assesses a proportion of correct predictions (Table 5). These values are not especially high, suggesting that the model was not properly specified and/or other variables not included on the survey were important.

A modified regression mode was run without the previously mentioned independent variables (model 2) to evaluate the impact of excluding the variables potentially causing multicollinearity problems (Table 6).

The likelihood ratio test, which uses a $\chi^{2}$ distribution, was used to determine if model 2 was significant. The likelihood

Table 5. Pseudo $\mathrm{R}^{2}$ values.

\begin{tabular}{llll}
\hline Measure & Model 1 & Model 2 & Formula \\
\hline Cragg-Uhler & 0.2955 & 0.2407 & $(1-\exp (-\mathrm{R} / \mathrm{N})) /$ \\
McFadden & 0.1813 & 0.1441 & $\mathrm{R} / \mathrm{U}$
\end{tabular}

Table 6. Corresponding $\boldsymbol{\beta}$ values for model 2.

\begin{tabular}{llc}
\hline Variable & $\beta_{\text {'s }}$ & Numeric value \\
\hline Intercept & $\beta_{0}$ & 0.507417 \\
Gender & $\beta_{1}$ & 0.649682 \\
Age1 & $\beta_{2}$ & -1.450874 \\
Age2 & $\beta_{3}$ & 0.393127 \\
Age4 & $\beta_{4}$ & -1.057676 \\
Education2 & $\beta_{6}$ & -1.677965 \\
Education3 & $\beta_{7}$ & -0.641793 \\
Education4 & $\beta_{8}$ & -1.219091 \\
Education6 & $\beta_{9}$ & 0.222361 \\
Region1 & $\beta_{14}$ & 0.642748 \\
Region3 & $\beta_{15}$ & 0.378596 \\
AreaRaised1 & $\beta_{16}$ & -0.22198 \\
AreaRaised2 & $\beta_{17}$ & -0.273058 \\
AreaRaised4 & $\beta_{18}$ & 0.182307 \\
AreaReside1 & $\beta_{19}$ & 0.088404 \\
AreaReside2 & $\beta_{20}$ & 0.961657 \\
AreaReside4 & $\beta_{21}$ & 0.043463 \\
Household1 & $\beta_{22}$ & 0.101815 \\
Household3 & $\beta_{23}$ & -1.538715 \\
Household4 & $\beta_{24}$ & -1.468615 \\
Household5 & $\beta_{25}$ & -0.150528 \\
Duties2 & $\beta_{26}$ & -0.530383 \\
Duties3 & $\beta_{27}$ & 0.311920 \\
Duties4 & $\beta_{28}$ & -1.891497 \\
Duties5 & $\beta_{29}$ & -0.461981 \\
Duties6 & $\beta_{30}$ & -0.263164 \\
Duties7 & $\beta_{31}$ & -1.154150 \\
Income1 & $\beta_{32}$ & 1.047749 \\
Income3 & $\beta_{33}$ & -0.135845 \\
\hline & &
\end{tabular}

ratio value for model 2 was 34.712 . The model proved to be useful at the $10 \%$ significance level because the calculated value of 34.712 is less than the $\chi^{2}$ tabulated value of 37.92 with 28 degrees of freedom. Model 2 may prove more useful than the full model in estimating participation as a result of the problem of multicollinearity being reduced.

The calculation of the probability for participation in U\&CF programs using model 2 was:

$$
\begin{gathered}
\text { Participation }=0.507417+0.649682(\text { Gender }=1) \\
+0.393127(\text { Age } 2=1)+0.222361(\text { Education6 }=1) \\
+0.642748(\text { Region } 1=1)+0.088404(\text { AreaReside } 1=1) \\
-0.311920(\text { Duties } 3=1)-0.135845(\text { Income } 3)
\end{gathered}
$$

If model 2 is applied to the same individual that was used in the earlier example, the parameters result in all 1's being plugged into the model and participation equals 2.055974 . This converts to a probability of 0.88654987 , which indicates that there is an $88.65 \%$ chance she will participate in U\&CF programs. Because $0.8865>0.5$, this leads to the conclusion the she is very likely to be participating in U\&CF programs.

There was a $4.8 \%$ decrease in the probability of participation with the use of model 2 . Both models may both be very 
successful in determining the likelihood of participation in $\mathrm{U} \& \mathrm{CF}$ programs.

Education2 (high school) and Duties4 (educator) proved to be significant at the $5 \%$ level indicating that these variables have a large effect on participation. U\&CF program planners should pay close attention to the characteristics defined by the previously mentioned variables when targeting individuals for participation.

Our results are consistent with other research on factors affecting participation in volunteer organizations. All the variables identified in the final model are considered primary determinants of participation (Natural Resources Conservation Service 2004). Other studies that discuss determinants of participation consistently use the type of variables in the models discussed here (Smith 1994). Pseudo $R^{2}$ values are not high. Analysts using biologic or physical data would generally be unhappy with these results. However, for social data of this type and the logit model formulation, these $\mathrm{R}^{2}$ levels are usually considered acceptable (Maddala 2001). We were satisfied that these results are significant and do illustrate valuable explanatory relationships that can be used to estimate participation levels.

Note that we were limited to data included in the 2003 survey. This model is merely a starting point in establishing factors that affect participation. Additional data will surely strengthen the model. Our main contribution is showing that this technique can be used effectively to estimate participation and we provide a starting point for a more detailed study.

Can a model like this be used in day-to-day work of the U\&CF professional? Yes, it does provide valuable information. Notice in our prior example of the 35 year old female forestry consultant that we determined the likelihood of her participation. The variables in the model interact and a simple table of likelihoods by characteristic would be too complex to be usable. However, other variables can be held constant and changes in variables like income level or age can be evaluated. The model certainly can be used to estimate likelihood of participation for any individual and would show the program planner where to best spend his or her time.

\section{CONCLUSION}

The purpose of this study was to provide insight into participation within U\&CF programs. A logistic regression model was used with independent variables being qualitative. Two econometric models were evaluated-one using all the available independent variables (model 1) and the other omitting certain variables (model 2 ). The pseudo- $\mathrm{R}^{2}$ values were not especially high, but they suggest a level of predictability. These low values could mean the model was not properly specified or that relevant variables were omitted. For an econometric study of this type, these are acceptable $\mathrm{R}^{2}$ values.

The two models proved to be significant (at the 10\% level) in the prediction of participation. Model 2 may prove more useful than the full model in estimating participation as a result of the problem of multicollinearity being corrected.

Acknowledgments. Support for this research was provided by a USDA Forest Service Urban and Community Forestry Assistance Grant awarded through the South Carolina Forestry Commission.

\section{LITERATURE CITED}

Alig, R.J., F. Bedford, R.J. Moulton, and L. Lee. 1999. Longterm projection of urban and developed land area in the United States. In: Keep America Growing, Balancing Working Lands and Sevelopment: Conference Proceedings (CD-ROM). American Farmland Trust, Washington, DC. Additional information at: www.farmland.org/ (accessed 11/4/05).

Alig, R.J., A.J. Plantinga, S. Ahn, and J.D. Kline. 2003. Land Use Changes Involving Forestry in the United States 1952 to 1997, With Projections to 2050. USDA Forest Service General Technical Report PNW-GTR-587.

Allison, P.D. 1999. Logistic Regression Using the $S A S^{R}$ System: Theory and Application. SAS Institute, Cary, NC, p. 46-51.

Andresen, J.W. 1989. Tree City USA: volunteer urban forestry. Journal of Arboriculture 13:333-343.

Bloniarz, D.V., and H.D.P. Ryan III. 1996. The use of volunteer initiatives in conducting urban forest resource inventories. Journal of Arboriculture 22:75-82.

Cole, D.W. 1979. Oakland urban forestry experiment: a cooperative approach. Journal of Forestry 77:417-419.

Cubbage, F.W., J. O'Laughlin, and C.S. Bullock. 1993. Forest Resource Policy. Wiley, New York, NY.

Heimlich, R.E., and W.D. Anderson. 2001. Development at the Urban Fringe and Beyond: Impacts on Agriculture and Rural Land. USDA Economic Reporting Service Agricultural Economic Report No. 803.

Henderson, N. 1984. Tapping the volunteer spirit: commitment in the Sierra. American Forests 90:33-36.

Iles, J.K. 1998. Inclusive urban and community forestry programs: using all of your community's cultural resources. Journal of Arboriculture 24:316-321.

London, J.B., and N.L. Hill. 2000. Land Conversion in South Carolina: State Makes the Top 10 List. Jim Self Center on the Future, Clemson University, Clemson, SC.

Maddala, G.S. 2001. Introduction to Econometrics, Third Edition. John Wiley, Chichester, UK.

Natural Resources Conservation Service. 2004. Guide for Estimating Participation in Conservation Programs and Projects. Technical Note, Series No. 1801, 2nd Revision. Greensboro, NC.

SAS Institute Inc. 2002. The SAS System for Windows Version 9.0. SAS Institute Inc., Cary, NC. 
SC Forestry Commission. 2005. Urban and Community Financial Assistance Program. http://www.state.sc.us/ forest/ucfgrantbr.pdf (accessed 11/04/05).

Smith, D.H. 1994. Determinants of voluntary association participation and volunteering-A literature review. Nonprofit and Voluntary Sector Quarterly 23:243-263.

Sommer, R. 1996. The value of resident participation in tree planting. Arborist News 5:43-44.

Straka, T.J., A.P. Marsinko, and C.J. Childers. 2005. Individual characteristics affecting participation in urban and community forestry programs in South Carolina. Journal of Arboriculture 31:129-135.

U.S. Department of Commerce, Bureau of the Census. 2000. Population Projections, Median Level. Washington, DC. http://www.census.gov/population/www/projections (accessed 8/17/06).

Urban Forestry South Expo. 2005. Urban Forestry Manual. http://www.urbanforestrysouth.org/Resources/ Collections/Collection.2005-06-02.0039 (accessed 11/04/ 05).

Vesterby, M., and K.S. Krupa. 2001. Major Uses of Land in the United States, 1997. Washington, DC, Economic Reporting Service Statistical Bulletin No. 973.

Wall, B.W., T.J. Straka, and S.E. Miller. 2006. An econometric study of the factors influencing participation in urban and community forestry programs in the United States. Arboriculture \& Urban Forestry 32(5):221-228.

Westphal, L., and G. Childs. 1994. Overcoming obstacles: creating volunteer partnerships. Journal of Forestry 92: $28-32$.

\section{J. Jess Fleming}

Graduate Research Assistant

Department of Forestry and Natural Resources

Clemson University

Box 340317

Clemson, SC 29634-0317, U.S.

Thomas J. Straka (corresponding author)

Professor

Department of Forestry and Natural Resources

Clemson University

Box 340317

Clemson, SC 29634-0317, U.S.

tstraka@clemson.edu
Stephen E. Miller

Professor

Department of Applied Economics and Statistics

Clemson University

Box 340313

Clemson, SC 29634-0313, U.S.

smllr@clemson.edu

Zusammenfassung. Von einer bundesweiten Erhebung unter den Einwohnern von Südkarolina über die Teilnahme an urbanen Forstprogrammen wurde ein ökonometrisches, auf Regression basierendes Modell generiert. Das ökonometrische Modell versucht, die Wahrscheinlichkeit einer individuellen Teilnahme zu schätzen. Die Ergebnisse können die Effektivität der Programmplanung und Organisation innerhalb der Forstkommission verstärken. Das Modell 1 war wie folgt konzipiert: Teilnahme $=F$ (Geschlecht, Alter, Ausbildung, Familienstand, Region, erhobene Fläche, Haushalt, Pflichten, Einkommen). Weil diese Antworten einen qualitativen Wert darstellen, wurden eine Anzahl von leeren Variablen (0 oder 1 z.B. für Ja oder Nein) generiert, um die Werte der Teilnahme besser zu reflektieren und es wurde ein Logit-Modell verwendet. Die LogitRegressionsanalyse produziert einen Wert zwischen 0 und 1, der als Wahrscheinlichkeit interpretiert werden kann. Modell 2, mit weniger Variablen, wurde später entwickelt, um mögliche multikollineare Probleme zu reduzieren. Modell 1 hatte eine Pseudo- $\mathrm{R}^{2}$ Wert von 0.2955 oder eine Wahrscheinlichkeit von $29,55 \%$, die richtige Vorhersage für die Teilnahme zu treffen. Modell 2 hatte einen Pseudo-R ${ }^{2}$ Wert von 0.2407. Die Modelle produzierten brauchbare Vorhersagen für die Teilnahme.

Resumen. Se generó un modelo de regresión econométrico de un censo a los residentes de South Carolina concerniente a la participación en programas forestales urbanos y comunales (U\&CF, por sus siglas en inglés). El modelo intenta estimar la probabilidad de participación. Los resultados se dirigen a incrementar la efectividad de los programas de planeación y organización dentro de las comisiones estatales forestales. El Modelo 1 fue creado como sigue: Participación = F (Género, Edad, Educación, Estado Marital, Región, Área Económica, Área Residencial, Familia, Impuestos e Ingresos). Debido a que las respuestas representan valores cualitativos, fueron generados un número de variables ficticias $(0$ o 1 , por ejemplo, para sí o no) para reflejar más precisamente los valores para participación y fue empleado un modelo "logit". El análisis de regresión logit produce un valor entre 0 y 1 que puede ser interpretado como una probabilidad. El modelo 2, con menos variables, fue creado más tarde para reducir posibles problemas de multicolinearidad. El modelo 1 tuvo un pseudo-valor $\mathrm{R}^{2}$ de 0.2955 , o un 29.55 por ciento de probabilidad de tener una predicción correcta de participación. El modelo 2 tuvo un pseudo-valor $\mathrm{R}^{2}$ de 0.2407 . Los modelos produjeron predicciones de participación razonables. 